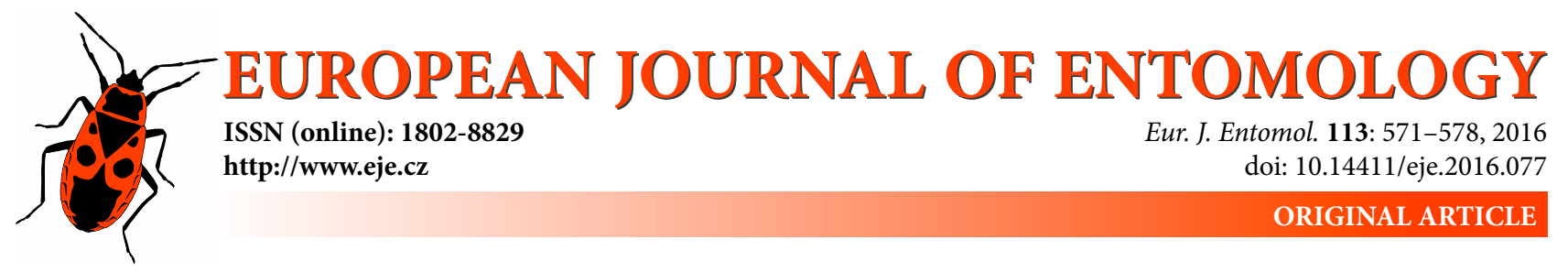

\title{
Variation of thorax flight temperature among twenty Australian butterflies (Lepidoptera: Papilionidae, Nymphalidae, Pieridae, Hesperiidae, Lycaenidae)
}

\author{
Gabriel NÈVE ${ }^{1,2}$ and CAsey HALL ${ }^{3}$ \\ ${ }^{1}$ Aix-Marseille Univ., Avignon Univ., IMBE, CNRS, IRD, 3 place Victor Hugo, 13331 Marseille Cedex 3, France; \\ e-mail: gabriel.neve@imbe.fr \\ ${ }^{2}$ School of Biological Sciences, Flinders University, GPO Box 2100, Adelaide, South Australia 5001, Australia \\ ${ }^{3}$ School of Biological Sciences, University of Adelaide, South Australia 5005, Australia; e-mail: casey.hall@adelaide.edu.au
}

Key words. Lepidoptera, Papilionidae, Nymphalidae, Pieridae, Hesperiidae, Lycaenidae, thorax flight temperature, wing loading, infra red thermometer, warming-up rate, physical constraint, allometry

\begin{abstract}
Thermal requirements for flight in butterflies is determined by a combination of external factors, behaviour and physical constraints. Thorax temperature of 152 butterflies was monitored with an infra-red thermometer in controlled laboratory conditions. The temperature at take-off varied from $13.4^{\circ} \mathrm{C}$, for a female Heteronympha merope to $46.3^{\circ} \mathrm{C}$, for a female Junonia villida. Heteronympha merope, an understorey species, had the lowest recorded take-off temperatures, with females flying at a much lower thorax temperatures than males. Among the tested butterfly species, warming-up rate was positively correlated with take-off temperature and negatively with body mass. Wing loading is a major variable in determining the thorax flight temperature. Butterflies with the highest wing-loadings experienced the highest thorax temperatures at take-off. A notable exception to this rule is Trapezites symmomus, the only Hesperiidae of our data set, which had thorax flight temperatures of $31.5^{\circ} \mathrm{C}$ and $34.5^{\circ} \mathrm{C}$, well within the range of the observed butterflies, despite a wing load ca. five times higher. The high thorax temperature recorded in $J$. villida is probably linked to its high flight speed. The results highlight the importance of physical constraints such as body size on the thermal requirements for flight across a range of butterfly species.
\end{abstract}

\section{INTRODUCTION}

Butterflies, being facultative endotherms (Bartholomew, 1981), rely on both external factors and internally produced heat for the maintenance of their body temperature. The thorax temperature depends on ambient temperature, irradiant heat gained by basking behaviour and heat generated by muscle movements, while heat loss occurs through body irradiance and air convection around the body (Wickman, 2009). Thermoregulation in insects is therefore dependant ultimately on behaviour, either directly through shivering or basking, or indirectly by moving to or away from sunlit patches (Kingsolver, 1985a). Butterflies of the genera Papilio, Colias and Pieris, need a thorax temperature between 28 and $42^{\circ} \mathrm{C}$ for flight, while rigorous flight is restricted to thorax temperatures between 33 and $38^{\circ} \mathrm{C}$ (Kingsolver, 1985b; Srygley \& Chai, 1990). The lowest recorded flight thorax temperatures are found in large species, such as Parnassius phoebus, which may fly with a thorax temperature of 17 to $20^{\circ} \mathrm{C}$ (Guppy, 1986).

The wing loading, defined as $p_{w}=m / S$, where $m$ is the total individual mass and $\mathrm{S}$ the total wing surface is a major variable determining the energy required for insect flight (Heinrich, 1986). Compared with other insects, butterflies have much lower wing loading values, suggesting that wing size and shape in butterflies evolved not only for flight functions, but also for other functions such as thermoregulation, sexual behaviour, mimicry and camouflage (Dudley, 1991). Wing loading generally increases with body mass in butterflies (Heinrich, 1986; Dudley, 1990), but skipper butterflies (Hesperiidae) are heavier than other butterflies of the same wing surface (see below). Species with a high wing loading require faster wing beats, and hence a higher thorax flight temperature (Bartholomew \& Casey, 1978). Thorax flight temperature in moths (Noctuidae and Geometridae) has been reported as correlated with wing loading (Bartholomew \& Heinrich, 1973) or with mass (Casey \& Joos, 1983). In butterflies, the data are sparse. As wing loading and mass are usually correlated, it is difficult to disentangle these two effects (Dudley, 1990; Heinrich, 1986).

The aims of this study were to document variation of thorax temperature among the studied species, and to test the effect of wing loading and mass on thorax flight temperature. Interspecific variation in thorax temperature needed 
for flight can have a significant impact on species fitness. For example, the ability to fly at lower temperatures may lead to more time available for dispersal and searching for mates and food (Kingsolver, 1983). Conversely, the more thorax temperature increases above ambient air temperature, the greater the risk of overheating, potentially leading to reduced survival and fitness. For example, in Colias butterflies, a thorax temperature of above $40^{\circ} \mathrm{C}$ causes individuals to cease flying to avoid overheating (Kingsolver $\&$ Watt, 1983). With the predicted increase in global temperatures and frequency of extreme temperatures, it is increasingly important to understand physical constraints on thermal tolerances which ultimately impact species fitness and dispersal ability.

Within a locality, the temperatures experienced by individual butterflies will largely depend on both their habitat preferences and timing of flight activity. Generally, species inhabiting forests will experience more stable conditions than species found in open habitats. A previous study, carried out in Mediterranean France (Nève, 2010), suggested that forest habitat species show lower thorax flight temperatures compared to open habitat species because of the lower temperature of the forest floor relative to open habitats. A secondary aim of the present study was to test this hypothesis with the available Australian species.

\section{MATERIAL AND METHODS}

A total of 152 butterflies were captured with hand nets (Upton \& Mantle, 2010) in the field, 85 near Adelaide (mainly Bedford Park $35^{\circ} 01^{\prime} \mathrm{S}, 138^{\circ} 34^{\prime} \mathrm{E}$ and Wotton Scrub, 34 $59^{\circ} \mathrm{S}, 138^{\circ} 47^{\prime} \mathrm{E}$, South Australia) and 67 at Cedar Creek, $27^{\circ} 49^{\prime} \mathrm{S}, 153^{\circ} 11^{\prime} \mathrm{E}$ (Queensland) (Table 1); only Pieris rapae was collected at both locations. The tested specimens belonged to twenty species, mostly from open habitat, or linked with the canopy (e.g. Graphium sarpedon). Only four species were specialist understorey species (pers. observ., Braby, 2000): Trapezites symmomus, Melanitis leda, Heteronympha merope and Nacaduba kurava.

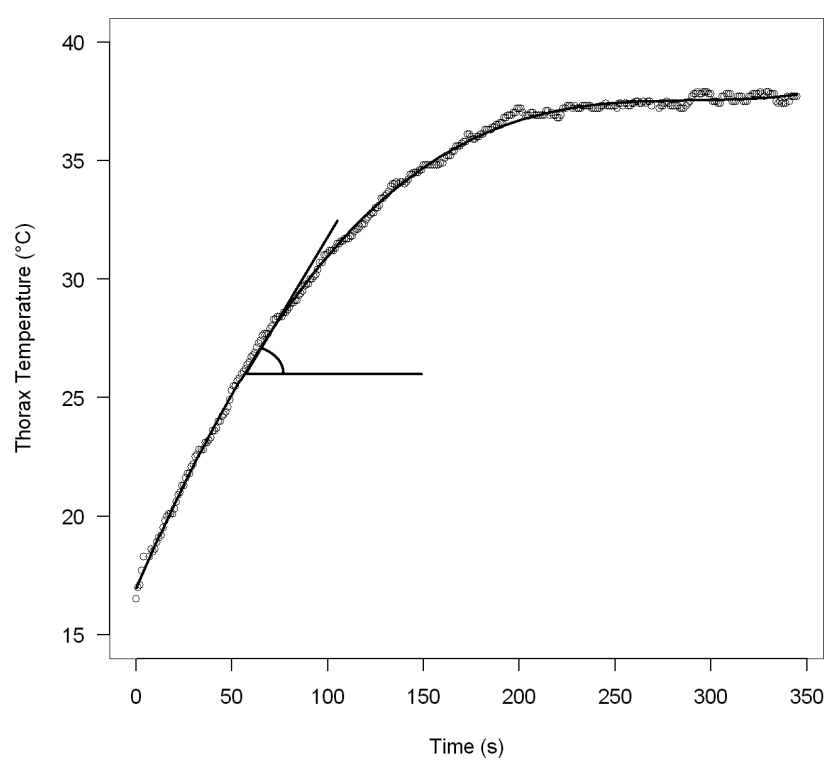

Fig. 1. Example of individual warming up process, here a male Pieris rapae. The solid line indicates the $4^{\text {th }}$ degree function fitted to the raw data. Its derivative at $\mathrm{y}=26^{\circ} \mathrm{C}$ gives the warming up rate at this temperature, here $0.13^{\circ} \mathrm{C} / \mathrm{s}$, indicated by the slope at this point.

Upon capture, specimens were put into glassine envelopes and cooled to ca. $11^{\circ} \mathrm{C}$ in a portable fridge. The same day, in an air conditioned room at 22 to $25^{\circ} \mathrm{C}$ lit with fluorescent lamps, each specimen was taken out of the fridge and placed on a piece of cotton under a $150 \mathrm{~W}$ neodynium daylight lamp, giving an irradiance of ca. $280 \mathrm{~W} / \mathrm{m}^{2}$ at the butterfly level. The thorax temperature of each specimen was measured with a testo $(895$ IR thermometer with the emissivity set at $\varepsilon=0.95$, and the recorded temperature was automatically input into a computer database, one datum per second. The behaviour of individuals was reported as they were warming up, especially the basking behaviour, and the position of the wings. The take-off temperature was taken as the last temperature recorded before the butterfly took off. A 4-th degree curve was fitted to the raw data, and its slope was used to estimate the

Table 1. Numbers of individuals tested per species and sex, with measured total wing surfaces and weights.

\begin{tabular}{|c|c|c|c|c|c|c|c|c|c|c|}
\hline \multirow[t]{2}{*}{ Family } & \multirow[t]{2}{*}{ Subfamily } & \multirow[t]{2}{*}{ Species } & \multirow[t]{2}{*}{$\begin{array}{c}\text { State } \\
\text { of Capture }\end{array}$} & \multirow[t]{2}{*}{ Females } & \multirow[t]{2}{*}{ Males } & \multirow{2}{*}{ Total } & \multicolumn{2}{|c|}{$\begin{array}{c}\text { Mean total } \\
\text { Wing surfaces } \\
\left(\mathrm{mm}^{2}\right) \\
\end{array}$} & \multicolumn{2}{|c|}{$\begin{array}{c}\text { Mean weights } \\
(\mathrm{mg})\end{array}$} \\
\hline & & & & & & & Females & Males & Females & Males \\
\hline Hesperiidae & Trapezitinae & Trapezites symmomus (Hübner, 1823) & Queensland & 0 & 2 & 2 & & 1086 & & 340 \\
\hline Papilionidae & Papilioninae & Graphium sarpedon (Linnaeus, 1758) & Queensland & 2 & 0 & 2 & 2200 & & 200 & \\
\hline Papilionidae & Papilioninae & Papilio aegeus (Donovan, 1805) & Queensland & 0 & 2 & 2 & & 4259 & & 399 \\
\hline Pieridae & Coliadinae & Catopsilia pomona (Fabricius, 1775) & Queensland & 5 & 4 & 9 & 2202 & 1847 & 276 & 208 \\
\hline Pieridae & Coliadinae & Catopsilia pyranthe (Linnaeus, 1758) & Queensland & 0 & 1 & 1 & & 1400 & & 116 \\
\hline Pieridae & Coliadinae & Eurema brigitta (Stoll, 1780) & Queensland & 1 & 3 & 4 & 513 & 432 & 31 & 31 \\
\hline Pieridae & Coliadinae & Eurema hecabe (Linnaeus, 1758) & Queensland & 3 & 3 & 6 & 488 & 581 & 43 & 26 \\
\hline Pieridae & Pierinae & Pieris rapae (Linnaeus, 1758) & Qld, Sth Austr. & 1 & 20 & 21 & 1050 & 959 & 70 & 58 \\
\hline Pieridae & Pierinae & Belenois java (Linnaeus, 1758) & South Australia & 0 & 2 & 2 & & 1373 & & 130 \\
\hline Nymphalidae & Satyrinae & Melanitis leda (Linnaeus, 1758) & Queensland & 8 & 8 & 16 & 1972 & 1878 & 1163,4 & 113 \\
\hline Nymphalidae & Satyrinae & Hypocysta adiante (Hübner, 1831) & Queensland & 1 & 0 & 1 & 529 & & 33 & \\
\hline ymphalidae & Satyrinae & Hypocysta metirius (Butler, 1875) & Queensland & 1 & 2 & 3 & 355 & 461 & 22 & 16 \\
\hline Nymphalidae & Satyrinae & Geitoneura klugii (Guérin-Méneville, 183 & ) South Australia & 0 & 1 & 1 & & 633 & & 52 \\
\hline Nymphalidae & Satyrinae & Heteronympha merope (Fabricius, 1775) & South Australia & 18 & 32 & 50 & 1935 & 1402 & 173 & 111 \\
\hline Nymphalidae & Nymphalinae & Hypolimnas bolina (Linnaeus, 1758) & Queensland & 1 & 2 & 3 & 2791 & 2181 & 255 & 208 \\
\hline Nymphalidae & Nymphalinae & Junonia villida (Fabricius, 1798) & South Australia & 11 & 3 & 14 & 908 & 777 & 103,6 & 83 \\
\hline Nymphalidae & Nymphalinae & Vanessa kershawi (McCoy, 1868) & South Australia & 1 & 0 & 1 & 1086 & & 127 & \\
\hline Nymphalidae & Biblidinae & Phaedyma shepherdi (Moore, 1858) & Queensland & 1 & 0 & 1 & 1464 & & 154 & \\
\hline Nymphalidae & Danainae & Euploea core (Cramer, 1780) & Queensland & 3 & 3 & 6 & 2351 & 2158 & 268 & 237 \\
\hline Nymphalidae & Danainae & Euploea tulliolus (Fabricius, 1793) & Queensland & 0 & 7 & 7 & & 2076 & & 173 \\
\hline Lycaenidae & Polyommatini & Nacaduba kurava (Moore, 1858) & Queensland & 0 & 1 & 1 & & 361 & & 25 \\
\hline
\end{tabular}




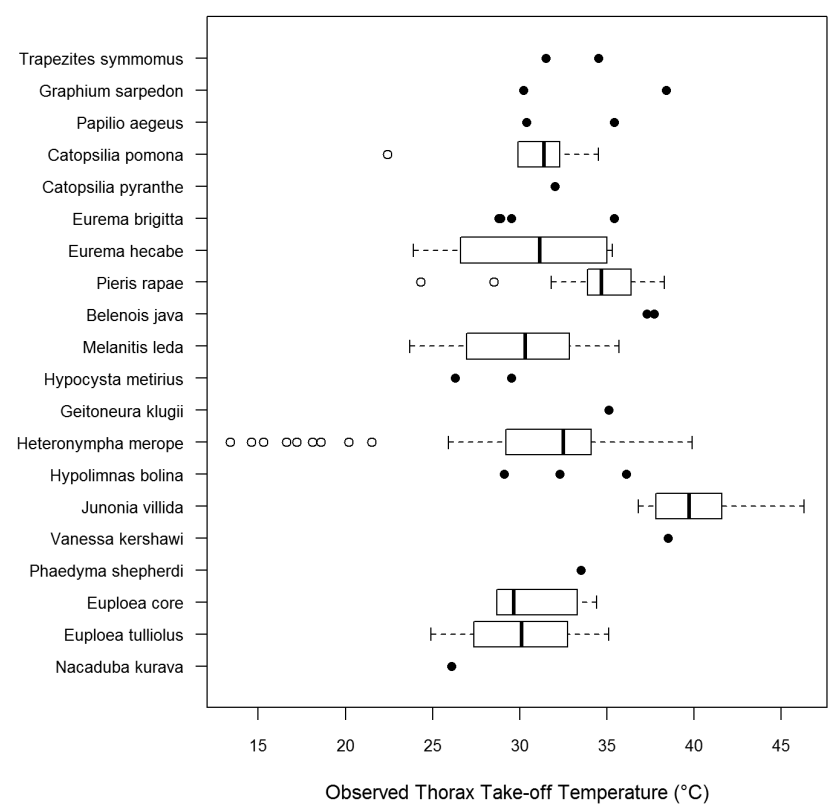

Fig. 2. Thorax take-off temperatures of twenty Australian butterfly species. The vertical lines indicate the median values, and the boxes the range from first to third quartile; dotted lines indicate extreme values if they fall within 1.5 times the interquartile difference, otherwise open circles indicates outliers. All data points are shown in filled circles for species with less than five data points.

rate of warming, in ${ }^{\circ} \mathrm{C} / \mathrm{s}$ (Fig. 1). The warming up rate at $26^{\circ} \mathrm{C}$ was used as an index of warming-up speed. This estimate was not possible on 21 specimens for which too few temperature points could be recorded during the warming-up process, hence the lower numbers of available warming-up rate estimates compared with available take-off temperatures.

As a control, three Heteronympha merope specimens were tested with a testo ${ }^{\circledR}$ thermocouple sensor set inside their thorax, at the same time as the outside thorax temperature was monitored. The temperature inside the thorax had a mean of $1.3^{\circ} \mathrm{C}$ warmer than the one measured on the surface, with a low variance of this difference $($ variance $=0.31)$.

After the warming-up experiment, each individual was weighed. Twenty-eight of the specimens were released after the experiment, while the rest were retained for references and measurements. These specimens were set with the trailing edge of the hind wing perpendicular to the thorax (Upton \& Mantle, 2010). All 125 set specimens were photographed in a standard way with a $60 \mathrm{~mm}$ Macro Canon Lens, together with a scale, and the total wing surface was estimated for each specimen using ImageJ (Rasband, 2012). The area of overlap between the forewing and the hind wing is taken into account only once, as this area is effective as a single area in the wing loading of flying butterflies (Dudley, 1990). The wing loading for each specimen was estimated as the ratio of the weight divided by the total wing surface.

All statistical analyses were performed using R (R Development Core Team, 2011). Differences in thorax temperatures at take-off between males and were investigated using t-tests, however only two species (Heteronympha merope and Melantis leda) had adequate numbers of both males and females for testing. Linear regression was used to assess the relationship between warming up rate and take-off temperature both among species and also within four species. Linear regression was also used to assess the relationship between wing loading and take-off temperature among species. Allometry between wing loading $p_{w}$ (in $\mathrm{mm}^{2}$ ) and body mass $w$ (in $\mathrm{mg}$ ) was studied directly using the $\mathrm{R}$

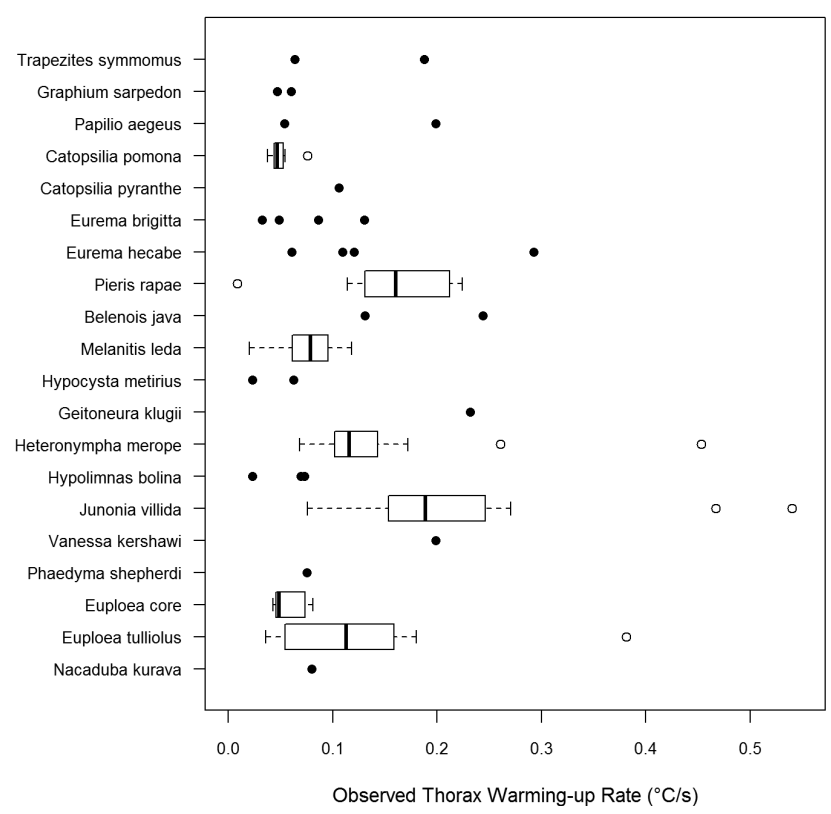

Fig. 3. Warming up speeds at $26^{\circ} \mathrm{C}$ for all tested Australian butterfly species. Symbols as in Fig. 2.

function $n l s$, a nonlinear regression modelling function, by fitting the power function $p_{w}=\mathrm{b} w^{a}$ directly rather than through its logarithmic transformation (Zar, 1968).

A total of 126 Pieris rapae specimens had been subjected to the same experimental design in France (Nève, 2010), and direct comparisons with that data set were performed where appropriate, using Wilcoxon Signed Rank tests in R.

Voucher specimens have been deposited either in the private collection of Roger Kitching (Griffith University) for Queensland species, or at the South Australian Museum, Adelaide, for South Australian species and Eurema species (South Australian Museum Accession numbers 31-015517 to 31-015538). Details of capture locations, take-off temperatures, body weights, and wing surfaces are given in the supplementary Table S1.

\section{RESULTS}

The observed take-off temperatures varied widely among species, ranging from 13.4 to $46.3^{\circ} \mathrm{C}$, with an amongspecies median value of $32.4^{\circ} \mathrm{C}$ (Fig. 2). The minimum temperature $\left(13.4^{\circ} \mathrm{C}\right)$ was recorded for a Heteronympha merope specimen, and the highest $\left(46.3^{\circ} \mathrm{C}\right)$ for a Junonia villida specimen. Warming-up rate at $26^{\circ} \mathrm{C}$ also varied widely among the twenty tested species, with the lowest values found in Melanitis leda $\left(0.02^{\circ} \mathrm{C} / \mathrm{s}\right)$ and Hypolimnas bolina $\left(0.02^{\circ} \mathrm{C} / \mathrm{s}\right)$ specimens. The highest value were found for Juniona villida $\left(0.54^{\circ} \mathrm{C} / \mathrm{s}\right)$ (Fig. 3$)$.

The two Nymphalidae forest understorey species, $\mathrm{Mel}$ anitis leda and Heteronympha merope, showed very similar take-off temperatures (Melanitis leda: mean $=30.2^{\circ} \mathrm{C}$, Heteronympha merope: mean $=30.3, t_{50}=0.04, P=0.97$; Fig. 4). In Heteronympha merope, females display a wider range of possible take-off temperatures, with a lower mean, than the males (females: from $13.4^{\circ} \mathrm{C}$ to $39.2^{\circ} \mathrm{C}$, mean $=25.2^{\circ} \mathrm{C}+/-\mathrm{sd} 7.9^{\circ} \mathrm{C}, \mathrm{n}=18$; males: from $16.6^{\circ} \mathrm{C}$ to $39.9^{\circ} \mathrm{C}$, mean $=33.2^{\circ} \mathrm{C}+/-\mathrm{sd}=3.9^{\circ} \mathrm{C}, \mathrm{n}=32$ ). The difference in take-off temperatures between males and females of $H$. merope is highly significant $\left(t_{22}=-4.00, P<0.001\right)$. 


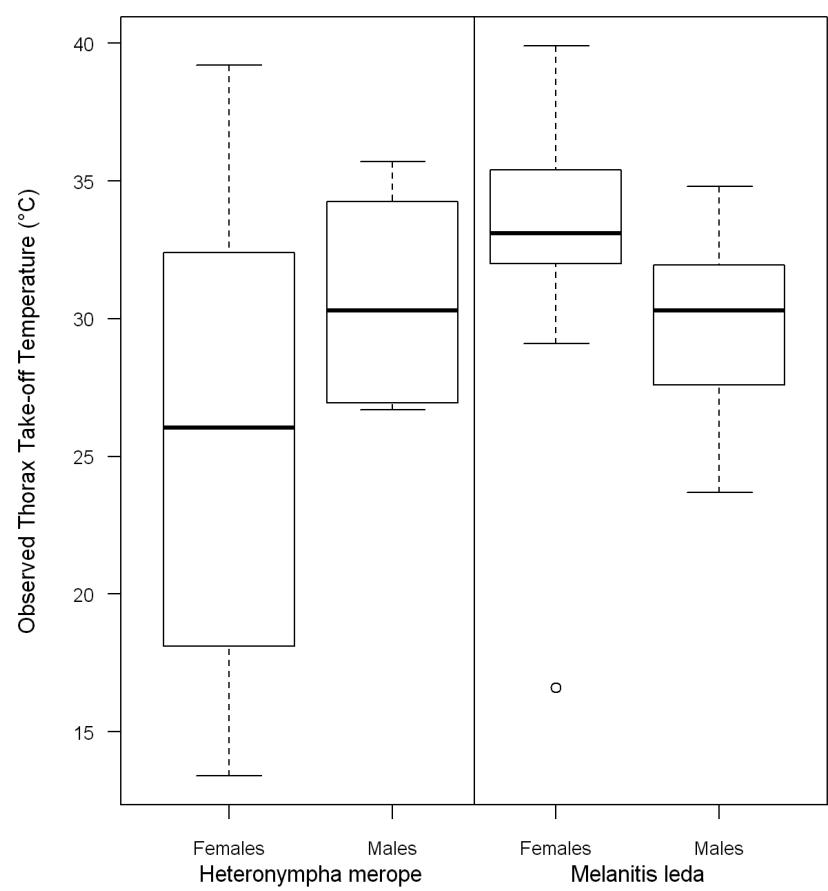

Fig. 4. Thorax temperatures at take-off for males and females of Heteronympha merope and Melanitis leda. The difference in temperatures between the sexes is highly significant in $H$. merope, but not in M. leda.

However, in Melanitis leda, there is no significant difference in take-off temperatures between the sexes $\left(t_{14}=0.49\right.$, $P=0.63$ ).

The species with the highest recorded thorax temperature was Juniona villida, with temperatures ranging from $36.8^{\circ} \mathrm{C}$ to $46.3^{\circ} \mathrm{C}$, implying an excess temperature (thorax temperature minus ambient temperature) of up to ca. $20^{\circ} \mathrm{C}$. The three species with the highest recorded take-off thorax temperatures were Juniona villida (median $=39.7^{\circ} \mathrm{C}$.), Belenois java $\left(\right.$ median $\left.=37.5^{\circ} \mathrm{C}\right)$ and Pieris rapae $($ median $=$ $34.7^{\circ} \mathrm{C}$ ). The latter species is the only non-native species in our data set, having been introduced from Europe (Lokkers \& Jones, 1999), allowing comparison with data from its natal range. Australian specimens of Pieris rapae flew with a temperature on average one degree warmer (median $=34.7^{\circ} \mathrm{C}, \mathrm{n}=20$ ) than the ones from France (median $=$ $33.7^{\circ} \mathrm{C}, \mathrm{n}=126 ; \mathrm{W}=821, P<0.05$, Fig. 5). Australian specimens also warm up more quickly (median $=0.16^{\circ} \mathrm{C} / \mathrm{s}$, $\mathrm{n}=19$ ) than French specimens (median $=0.12^{\circ} \mathrm{C} / \mathrm{s}$, $\mathrm{n}=126, \mathrm{~W}=618, P<0.001)$.

The among species variation of warming-up rate did correlate significantly with take-off temperature $\left(t_{18}=4.89\right.$, $P<0.001$, Fig. 6). When the species were looked at individually for the same relationship, among the ones for which at least ten individuals had been tested, only $\mathrm{Mel}$ anitis leda showed such a positive relationship $\left(t_{12}=2.66\right.$, $P=0.02$, Fig. 7).

With a value of $0.524 \mathrm{mg} / \mathrm{mm}^{2}$, Trapezites symmomus had a much larger wing loading than all other species, which had values ranging from $0.035 \mathrm{mg} / \mathrm{mm}^{2}$ (for Hypocysta metirius males) to $0.127 \mathrm{mg} / \mathrm{mm}^{2}$ (for Catopsilia pomona females). Trapezites symmomus is also the only species in

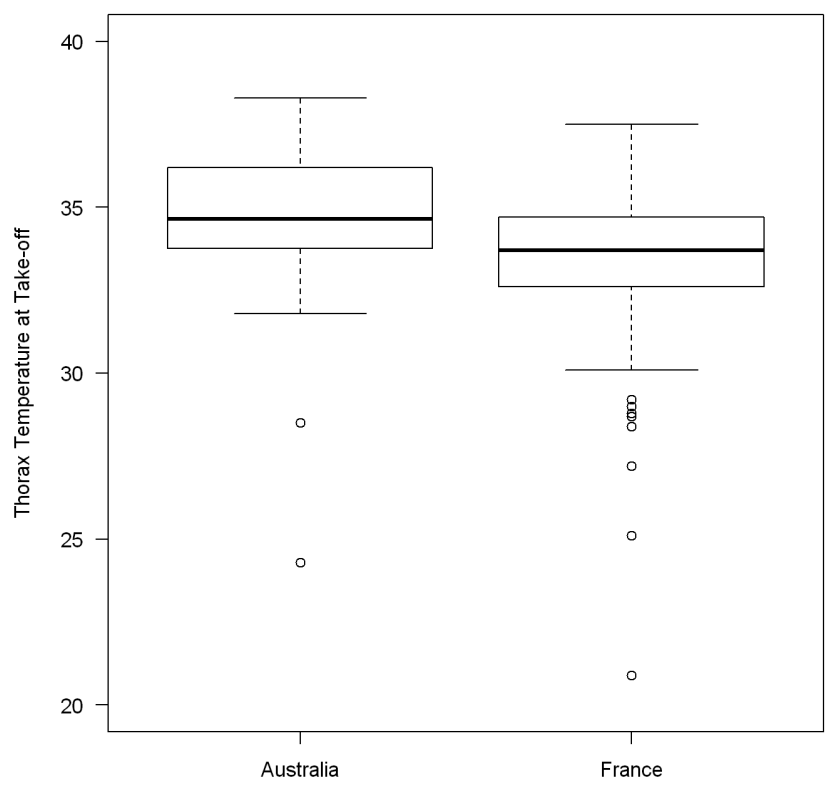

Fig. 5. Thorax take-off temperature for Cabbage White butterflies Pieris rapae, from Australia and France. Australian specimens have a take-off temperature on average $1^{\circ} \mathrm{C}$ warmer than the French specimens.

the data set to have a linear relationship between thorax temperature and time during the warming-up process, suggesting a different warming-up process than in other Lepidoptera lineages. Trapezites symmomus was then discarded from the data set for the analysis of the effect of wing load on take-off temperature. Among species variation showed that temperature at take-off was positively correlated with wing-loading $\left(t_{17}=2.28, P=0.036\right.$, Fig. 8$)$.

Wing loading $p_{w}$ and body mass $w$ were correlated by the allometric function $p_{w}=0.030 w^{0.225}(t=3.86$ and $t=4.31$, $P=0.001$ and $P<0.001$; Fig. 9).

\section{DISCUSSION}

Very few temperature data on the studied species has been published before. Notable exceptions are Papilio aegeus, Melanitis leda and Pieris rapae. Heinrich (1986) gave thorax temperatures of $35^{\circ} \mathrm{C}$ for Papilio aegeus flying in the shade and $42.8^{\circ} \mathrm{C}$ when flying in the sunshine. Our data on this species shows lower values $\left(30.4\right.$ and $\left.35.4^{\circ} \mathrm{C}\right)$. Studies by Kemp (2002) gave inside thoracic temperatures of Melanitis leda males ranging from 28.2 to $38.9^{\circ} \mathrm{C}$. Our data on the same species are lower, ranging from 23.7 to $34.8^{\circ} \mathrm{C}$. Even allowing for the difference between inside and outside (about $1.3^{\circ} \mathrm{C}$ ), our estimates in both cases remain lower, probably as a result of our laboratory conditions testing the thorax temperature from which flight is possible, rather the thorax temperature at which individuals usually fly or, in the latter case, perform their courtship.

Pieris rapae was the only species tested from European and Australian populations, and as such provides an interesting comparison between its native and introduced range. The $1^{\circ} \mathrm{C}$ higher thorax take-off temperature, and the quicker warming-up in Australia may be due its adaptation to the higher temperatures experienced in Australia compared with the native range. Such physiological plasticity 


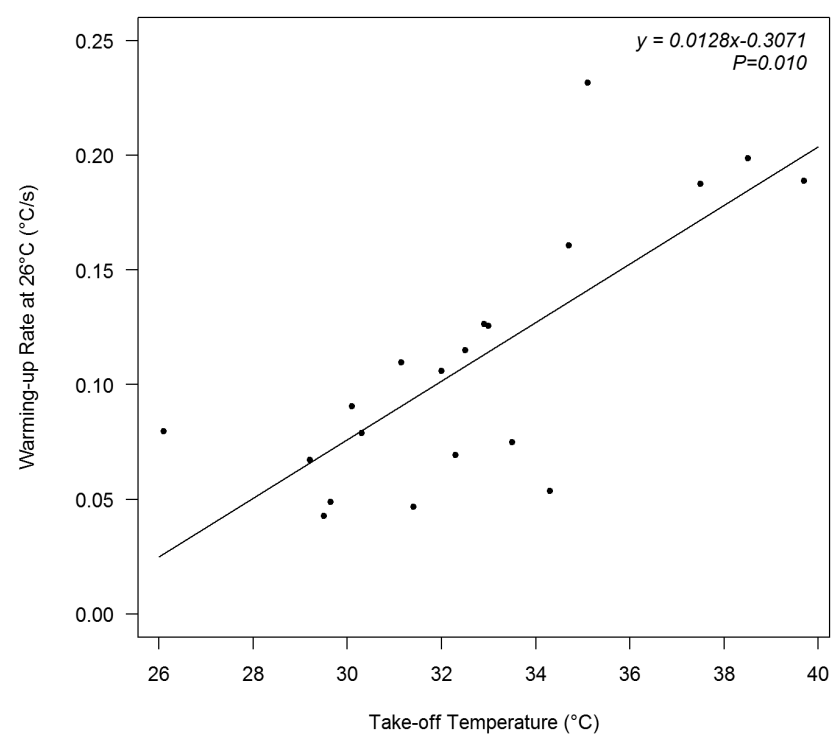

Fig. 6. Warming-up rate at $26^{\circ} \mathrm{C}$ as a function of take-off temperature, for median values observed in twenty Australian species.

in thermal requirements for flight may impact not only on the invasive ability of a species but also on its ability to adapt to climate change (Matilla, 2015).

As in European butterflies (Nève, 2010), understory specialists require a lower thorax temperature for flight activities when compared to open habitat species. Melanitis leda and Heteronympha merope are two butterflies active in the forest understorey; as such they experience cooler temperatures than species found in more open habitats (Wickman, 2009), and they have fewer opportunities to bask to gain higher temperatures. In Heteronympha merope, females may fly at a much lower thorax temperature than males. This sex difference is unusual, as females need a higher thorax temperature for flight than males in Colias philodice (Kingsolver, 1983) and in Thymelicus lineola (Pivnick \& McNeil, 1986), whereas no difference were found in Heodes virgaureae (Douwes, 1976). Unlike these species, $H$. merope shows mainly disjunct population peaks for males and females, with males most abundant in spring and females in autumn (pers. observ., Braby, 2000). The difference in flight thorax temperatures between males and females of $H$. merope may reflect the different climatic conditions experienced by each, and hence an adaptation to minimize excess temperature, thus reducing metabolic costs. Alternatively, differences between sexes may also reflect difference in wing shape and flight behaviour, as in the case of Pararge aegeria (Berwaerts et al., 2006).

Melanitis leda, unlike $H$. merope, flies mainly at dusk and dawn (Braby, 1995; Kemp, 2002, 2003), and may be present throughout the year in many localities (Braby, 2000). Their habit of flying during the coolest parts of the day may be linked to their low temperature requirements for flight activities.

The case of Juniona villida, with the highest recorded thorax temperatures, half of which close to or above $40^{\circ} \mathrm{C}$, raises interesting questions. Previous studies (Kingsolver \& Watt, 1983; Matilla, 2015) suggest that $J$. villida may be
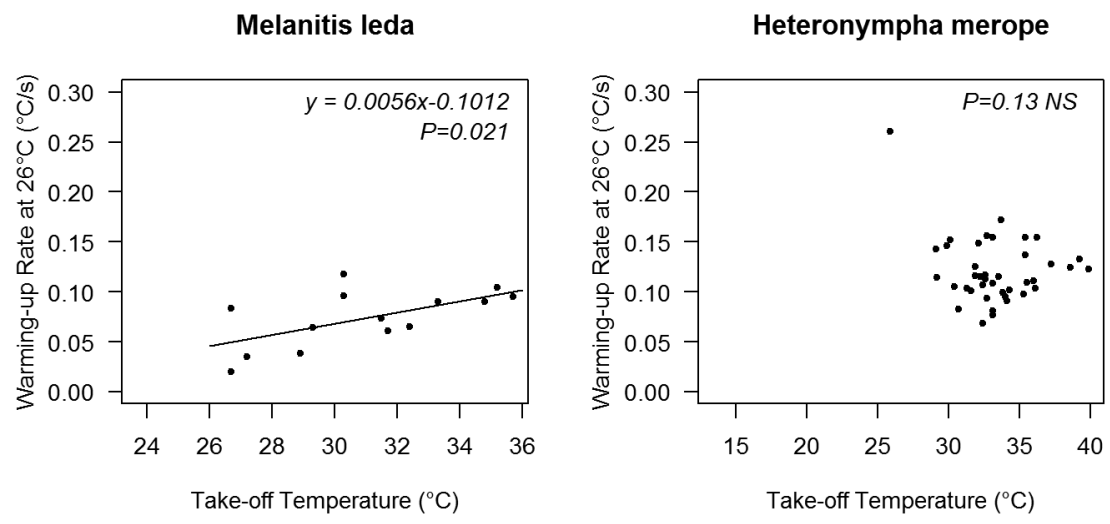

Pieris rapae
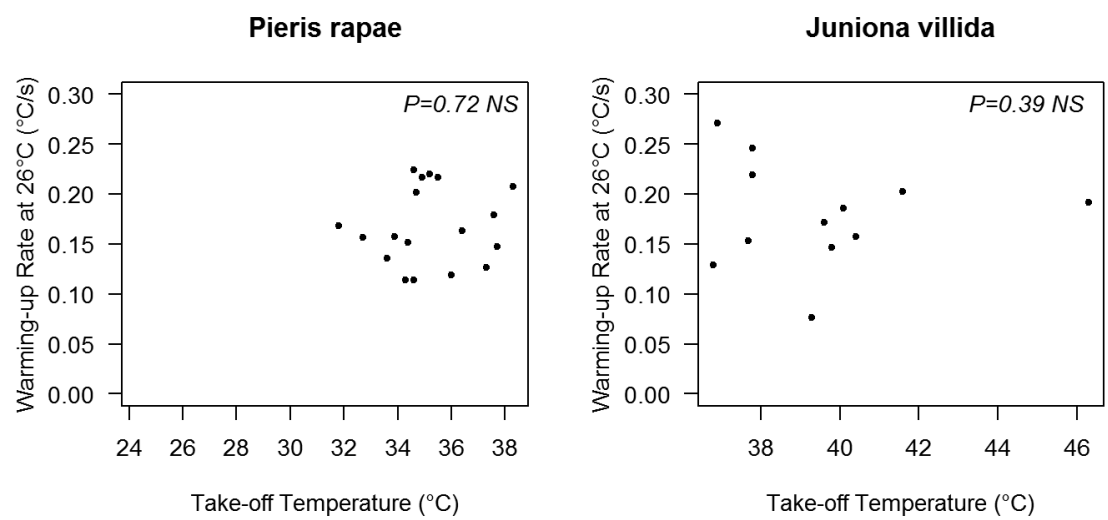

Fig. 7. Warming-up rate at $26^{\circ} \mathrm{C}$ as a function of take-off temperature, for four Australian species in which at least ten specimens had been tested. NS - not significant. The relationship is significant only in Melanitis leda. 


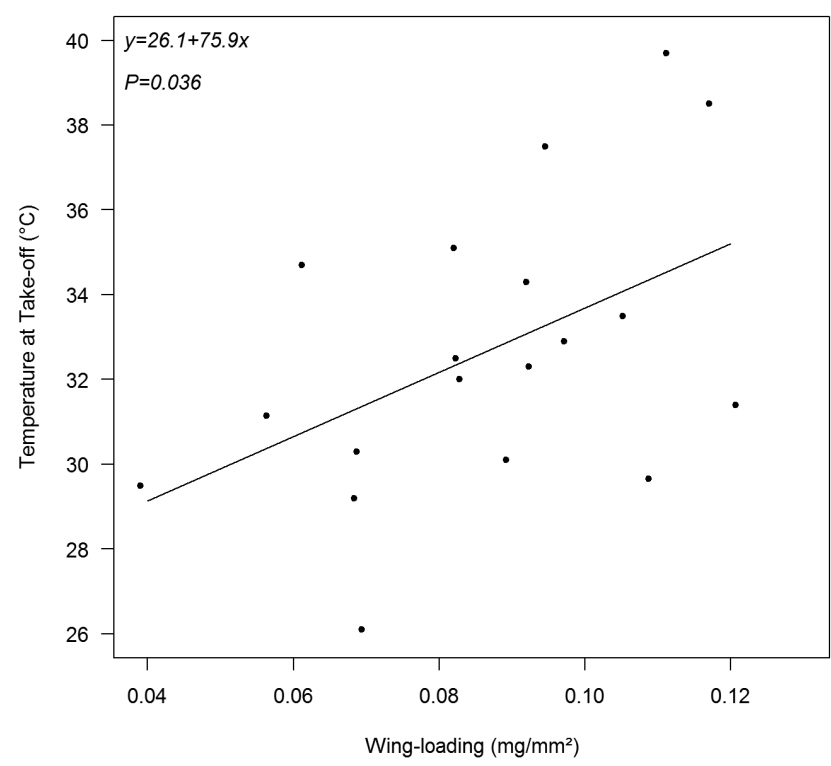

Fig. 8. Temperature at take-off according to wing loading for the 19 tested species (Trapezites symmomus is omitted; its wing loading is $0.524 \mathrm{mg} / \mathrm{mm}^{2}$ and median thorax temperature at take-off was $33^{\circ} \mathrm{C}$ ); dots indicate median values per species. The line indicates the linear correlation for all depicted points.

at risk of heat shock at such high temperatures. This species, however, has a flight pattern with quick reactions and fast flights (Braby, 2000; pers. observ.), suggesting a high amount of muscular activity and thus may have adapted to cope with higher than normal flight temperatures. Juniona villida may then be an extreme case of high wingbeat frequency related to a high temperature (Pivnick \& McNeil, 1986). This species seems thus to have evolved a fast escape strategy against insectivorous bird predators, which also requires high thorax flight temperature, as palatable species often do (Chai \& Srygley, 1990).

It should be noted that Trapezites symmomus, which has a wing loading ca. five times higher than all other tested butterflies only showed take off temperatures of $31.5^{\circ} \mathrm{C}$ and $34.5^{\circ} \mathrm{C}$, well within the range of the observed butterflies (Fig. 3). It has been shown that the genotypes of the individuals was a major determinant of the ambient temperature at which individual fly (Colias butterflies: Watt et al., 1983, Monarch Danaus plexippus: Hughes \& Zalucki, 1993). Whether Juniona villida holds special variants of the loci adapted to high temperature remains an open question.

In our data set, wing loading $p_{w}$ showed an allometric relationship with body mass $w\left(p_{w}=0.030 w^{0.225}\right)$. As the exponent is $<1$, this is a negative allometric relationship (Huxley \& Teissier, 1936; Gould, 1966) between wing loading and body mass. Dudley (1990) also obtained a negative allometry (which he erroneously called "positive allometry"), but with a much higher exponent (0.474); only a small part of the difference between our result and Dudley's are due to the use of the direct function for the estimate: an estimate using the classical log-log relationship gives an exponent factor of 0.238 with our data. It should be noted here that for comparative purposes, the exponent does not depend on the units being used, only the multiply-

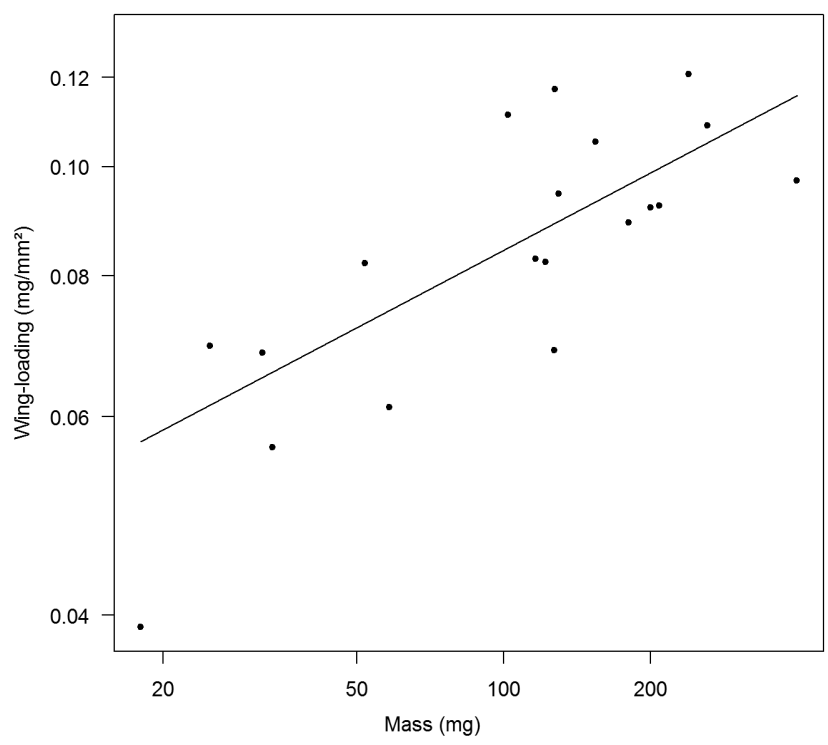

Fig. 9. Wing loading according to mass in 19 Australian butterflies. Trapezites symmomus is omitted; its wing loading is $0.524 \mathrm{mg} / \mathrm{mm}^{2}$ and its mass is $340 \mathrm{mg}$. Both scales are logarithmic. The fitted allometric function is $\mathrm{y}=0.030 \mathrm{x}^{0.225}$.

ing factor does; this was the cause of some debate between Huxley and Teissier (Gayon, 2000). Despite the fact that wing loading and body mass are correlated variables, our analysis clearly shows a correlation between thorax temperature at take-off and wing loading, but not with body mass. Heinrich (1986) could not differentiate these two effects, due to insufficient data. Our data shows that wing loading is more relevant than body mass in respect to thorax flight temperature.

In many insect species, the rate of warming-up is related to muscular activity and body mass, whereas heat loss depends of their external body surface, smaller individuals and species taking longer to warm up than large ones (May, 1976), although in within species comparison, the reverse has occasionally been found (Thymelicus lineola: Pivnick \& McNeil, 1986; Hypolimnas bolina: Kemp \& Krockenberger, 2004). In our experimental setting, when looking at multiple species comparison, large butterflies warm up more quickly than small ones. The lack of significance for tests in individual species may be due to the small sample sizes or lower variance of intra-specific variation compared with inter-specific variation.

In the present data set, there is also a trend for the butterflies to warm up faster if they have to reach a higher temperature for flight activity. In this way, the time spent to reach the needed temperature does not increase in proportion with the required flight temperature. However, the energy required to reach a high temperature must be accounted for. While solar energy pays a role in increasing body temperature in butterflies (Wasserthal, 1975), muscular activity is also needed to reach this temperature, especially, as in the case of Juniona villida, it is well above the ambient air temperature.

Species showing a low wing loading generally fly with lower wing beat frequencies than the ones with higher wing loadings (Casey \& Joos, 1983), and low wing beat 
frequencies require a lower thorax temperature for flight activity. It is thus no surprise that the species with the lowest take-off temperature, Eurema brigitta, Nacaduba kurava and Hypocysta adiante were also among the ones with the lowest wing loading and total weight. On the other hand, wing loading per se is not sufficient to infer the thorax temperature necessary for flight, as microhabitat and behaviour also have an influence.

The increase of thorax temperature of Trapezites symmomus in a linear fashion is similar to the sphinx moth Manduca sexta (Heinrich \& Bartholomew, 1971), while other butterflies generally show a curve with decreasing rates until the take-off temperature is reached in a plateau fashion (Nève, 2010). This may be related to the shape of these two species, which have a lower surface to volume ratio than butterflies of the families others than Hesperiidae; they have thus a lower heat loss rate (Heinrich, 2003). The increase in temperature is therefore mainly the result of the muscular activity, heat loss being negligible in comparison.

\section{CONCLUSIONS}

Temperature needs of butterflies are an important component of their ecological requirements (Wickman, 2009), both at the adult and larval stages (Serratore et al., 2013). The thorax temperature needed for flight activity is the result of multiple effects. Individual weight and total wing surface are physical factors influencing wing beat frequency, but individual differences in behaviour also plays a role. The optimal flight thorax temperature is adaptively determined through selection of enzymes variants active at specific temperatures. Species living in cooler environments, such as the forest understorey, may be adapted to fly at lower temperature as they would mainly rely on their muscular activity for thorax heating. The temperature needed for flight activity is thus the result of trade-off between environmental variables and internal physical and biochemical processes. The results highlight the importance of understanding this dynamic in the face of environmental change. While butterflies can behaviourally adapt to changes in temperature, factors such as body size and wing loading may impose physiological limits to future climate adaptation.

ACKNOWLEDGEMENTS. We wish to thank A. Thiéry, E. Meglécz and D. Mackay for help during the field work and for numerous discussions. R. Kitching introduced the two authors to each other, and he and B. Kitching allowed the field and laboratory work in Queensland to take place. Field work in South Australia was carried out with permit number A26006-1. No such permit was necessary in Queensland, as research there was not undertaken on protected grounds.

\section{REFERENCES}

Bartholomew G.A. 1981: A matter of size: an examination of endothermy in insects and terrestrial vertebrates. In Heinrich B. (ed.): Insect Thermoregulation. Wiley, New York, pp. 45-78.

Bartholomew G.A. \& CASEY T.M. 1978: Oxygen consumption of moths during rest, pre-flight warm-up, and flight in relation to body size and wing morphology. - J. Exp. Biol. 76: 11-25.
Bartholomew G.A. \& Heinrich B. 1973: A field study of flight temperatures in moths in relation to body weight and wing loading. - J. Exp. Biol. 58: 123-135.

Berwaerts K., Aerts P. \& Van Dyck H. 2006: On the sex-specific mechanisms of butterfly flight: flight performance relative to flight morphology, wing kinematics, and sex in Pararge aegeria. - Biol. J. Linn. Soc. 89: 675-687.

BRABY M.F. 1995: Seasonal changes in relative abundance and spatial distribution of Australian lowland tropical Satyrine butterflies. - Austr. J. Zool. 43: 209-229.

Braby M.F. 2000: Butterflies of Australia, their Identification, Biology and Distribution. CSIRO, Canberra, $976 \mathrm{pp}$.

CASEY T.M. \& Joos B.A. 1983: Morphometrics, conductance, thoracic temperature, and flight energetics of noctuid and geometric moths. - Physiol. Zool. 56: 160-173.

Chai P. \& Srygley R.B. 1990: Predation and the flight, morphology, and temperature of neotropical rain-forest butterflies. Am. Nat. 135: 748-765.

Douwes P. 1976: Activity in Heodes virgaureae (Lep., Lycaenidae) in relation to air temperature, solar radiation, and time of day. - Oecologia 22: 287-298.

DudLEy R. 1990: Biomechanics of flight in neotropical butterflies: morphometrics and kinematics. - J. Exp. Biol. 150: 37-53.

DudLEY R. 1991: Comparative biomechanics and the evolutionary diversification of flying insect morphology. In Dudley E.C. (ed.): The Unity of Evolutionary Biology: Proceedings of the Fourth International Congress of Systematic and Evolutionary Biology. Dioscorides Press, Portland, pp. 503-514.

GAYON J. 2000: History of the concept of allometry. - Am. Zool. 40: 748-758.

GouLD S.J. 1966: Allometry and size in ontogeny and phylogeny. - Biol. Rev. 41: 587-638.

Guppy C.S. 1986: The adaptative significance of alpine melanism in the butterfly Parnassius phoebus (Lepidoptera: Papilionidae). - Oecologia 70: 205-213.

HeInRICH B. 1986: Comparative thermoregulation of four montane butterflies of different mass. - Physiol. Zool. 59: 616626.

HeinRich B. 2003: Thermoregulation. In Resh V.H. \& Cardé R.T. (eds): Encyclopedia of Insects. Academic Press, San Diego, pp. 1119-1126.

HeinRich B. \& BARTholomew G.A. 1971: An analysis of pre-flight warm-up in the sphinx moth, Manduca sexta. - J. Exp. Biol. 55: 223-239.

Hughes J.M. \& Zalucki M.P. 1993: The relationship between the pgi locus and the ability to fly at low-temperatures in the monarch butterfly Danaus plexippus. - Biochem. Genet. 31: 521-532.

HuXley J.S. \& TeISSIER G. 1936: Terminology of relative growth. - Nature 137: 780-781.

Kemp D.J. 2002: Visual mate-searching behaviour in the evening brown butterfly, Melanitis leda (L.) (Lepidoptera: Nymphalidae). - Austr. J. Entomol. 41: 300-305.

KEMP D.J. 2003: Twilight fighting in the evening brown butterfly, Melanitis leda (L.) (Nymphalidae): age and residency effects. -Behav. Ecol. Sociobiol. 54: 7-13.

Kemp D.J. \& Krockenberger A.K. 2004: Behavioural thermoregulation in butterflies: the interacting effects of body size and basking posture in Hypolimnas bolina (L.) (Lepidoptera: Nymphalidae). - Austr. J. Zool. 52: 229-236.

Kingsolver J.G. 1983: Thermoregulation and flight in Colias butterflies: elevational patterns and mechanistic limitations. Ecology 64: 534-545.

Kingsolver J.G. 1985a: Butterfly engineering. - Scient. Am. 253: 106-113. 
KingSOLVER J.G. 1985b: Butterfly thermoregulation, organismic mechanisms and population consequences. - J. Res. Lepidopt. 24: $1-20$.

KingSOLVER J.G. \& WATT W. 1983: Thermoregulatory strategies in Colias butterflies - thermal stress and the limits to adaptation in temporally varying environments. - Am. Nat. 121: $32-55$.

LoKkers C. \& Jones R.E. 1999: The cabbage white, Pieris rapae (Pieridae). In Kitching R.L., Scheermeyer E., Jones R.E. \& Pierce N.E. (eds): Biology of Australian Butterflies, Monographs on Australian Lepidoptera, Vol. 6. CSIRO, Collingwood, pp. 153-172.

Matilla A.L. 2015: Thermal biology of flight in a butterfly: genotype, flight metabolism, and environmental conditions. Ecol. Evol. 5: 5539-5551.

MAY M.L. 1976: Warming rates as a function of body size in periodic endotherms. - J. Comp. Physiol. (B) 111: 55-70.

NÈvE G. 2010: Variation of flight thorax temperature among Mediterranean butterflies. - Entomol. Rom. 15: 21-24.

Pivnick K.A \& McNeIL J.N. 1986: Sexual differences in the thermoregulation of Thymelicus lineola adults (Lepidoptera: Hesperiidae). - Ecology 67: 1024-1035.

RASBAND W.S. 2012: ImageJ. U.S. National Institutes of Health, Bethesda, Maryland, URL: http://imagej.nih.gov/ij/.

R Development Core Team 2011: $R$ : A Language and Environment for Statistical Computing. R Foundation for Statistical Computing, Vienna, URL: http://www.R-project.org/.
Serratore V.R., ZAlucki M.P. \& CARTer P.A. 2013: Thermoregulation in moulting and feeding Danaus plexippus L. (Lepidoptera: Nymphalidae) caterpillars. - Austr. J. Entomol. 52: $8-13$

SRygley R.B. \& Chai P. 1990: Predation and the elevation of thoracic temperature in brightly colored neotropical butterflies. Am. Nat. 135: 766-787.

Upton M.S. \& Mantle B. 2010: Methods for Collecting, Preserving and Studying Insects and Other Terrestrial Arthropods. 5th ed. Australian Entomological Society, Canberra, 81 pp.

WASSERTHAL L.T. 1975: The rôle of butterfly wings in regulation of body temperature. - J. Insect Physiol. 21: 1921-1930.

WatT W.B., Cassin R.C. \& Swan M.S. 1983: Adaptation at specific loci. III. Field behaviour and survivorship differences among Colias Pgi genotypes are predictable from in vitro biochemistry. - Genetics 103: 725-739.

WICKMAN P.O. 2009: Thermoregulation and habitat use in butterflies. In Settele J., Shreeve T., Konvicka M. \& Van Dyck H. (eds): Ecology of Butterflies in Europe. Cambridge University Press, Cambridge, pp. 55-61.

ZAR J.H. 1968: Calculation and miscalculation of the allometric equation as a model in biological data. - BioScience 18: $1118-1120$.

Received August 31, 2016; revised and accepted November 14, 2016 Published online December 19, 2016

Supplementary file:

S1 (http://www.eje.cz/2016/077/S1.pdf). Data set with details for every specimen tested: Identifier, species, sex, wing surface, weight, date and location of capture, body temperature at takeoff, warming-up rate at $26^{\circ} \mathrm{C}$ and, if applicable, South Australian Museum voucher number. NA indicates missing data. 